\title{
First report of bovine herpesvirus 1 isolation from bull semen samples in China
}

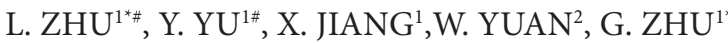

\begin{abstract}
${ }^{1}$ College of Veterinary Medicine and Jiangsu Co-innovation Center for Prevention and Control of Important Animal Infectious Diseases and Zoonoses, Yangzhou University, 48 Wenhui East Road, Yangzhou, 225009, P. R. China; ${ }^{2}$ Institute of Animal Sciences, Chinese Academy of Agricultural Sciences, No. 2 Yuanmingyuan West Road, Beijing, 100193, P. R. China
\end{abstract}

Received October 20, 2016; revised February 6, 2017; accepted October 12, 2017

\begin{abstract}
Summary. - Bovine herpesvirus 1 (BoHV-1) infection causes substantial economic losses to the cattle industry worldwide. So far, the isolation of BoHV-1 field virus has not been reported in China. Here, for the first time we report that two isolates of BoHV-1 designated as NJ16-1 and NJ16-2 were obtained from semen samples from breeding bulls in China. Typical cytopathic effect in MDBK cells, detection of viral protein VP16 in western blot analysis, PCR detection of BoHV-1 gB gene proved BoHV-1 infection and subsequent nucleotide sequence analysis showed a 99\% identity with BoHV-1 Cooper strain. These results suggest that these isolated viruses are BoHV-1.
\end{abstract}

Keywords: BoHV-1; virus isolation; VP16; CPE

Bovine herpesvirus 1 (BoHV-1) is an enveloped doublestranded DNA virus belonging to the family Alphaherpesvirinae, genus Varicellovirus (Tikoo et al., 1995), which is responsible for a variety of clinical syndromes, such as infectious bovine rhinotracheitis and infectious pustular vulvovaginitis in cows and balanoposthitis in bulls (Jones and Chowdhury, 2007; Muylkens et al., 2007). Acute infection of the respiratory tract by BoHV-1 can induce immunosuppression, which predisposes the cattle to develop secondary infection, severe pneumonia, and even death (Bielefeldt Ohmann and Babiuk, 1985; Tikoo et al., 1995). BoHV-1 infection causes great economic losses to the cattle industry worldwide. It costs the US cattle industry approximately 3 billion dollars annually (Jones and Chowdhury, 2007).

Following acute infection, BoHV-1 establishes latency in sensory neurons that reside within trigeminal ganglia

*Corresponding authors. E-mail: yzgqzhu@yzu.edu.cn (Guoqiang Zhu) and lzhu3596@163.com (Liqian Zhu); phone: (0086)-51487972590. "Co-first authors.

Abbreviations: $\mathrm{HBV}-1$ = bovine herpes virus 1; $\mathrm{TG}=$ trigeminal ganglia; $\mathrm{CPE}=$ cytopathic effect; $\mathrm{Gb}=$ glycoprotein $\mathrm{B} ; \mathrm{VP} 16=$ viron protein 16; PVDF = polyvinylidene difluoride
(Darling et al., 2014), and the infected cattle are estimated to be lifelong carriers and potential shedders of the virus (Jones, 2003; Jones and Chowdhury, 2010; Pawar et al., 2014). Reactivation from latency can be periodically induced by stress, followed by transmition of the virus between animals (Raaperi et al., 2014). Noticeably, the virus is excreted into semen from infected bulls during both acute phase of infection and latency (Pawar et al., 2014; van Oirschot et al., 1993), and insemination of cows with BoHV-1-contaminated semen by either natural service or artificial insemination leads to the animal infection (Sharifzadeh et al., 2015; Turin et al., 1999). The vaccination completely failed to prevent the shedding of the virus into the semen (Eaglesome and Garcia, 1997; Pawar et al., 2014). Hence, BoHV-1-contaminated semen from breeding bulls is considered to be an important resource of virus transmission.

The vaccines for BoHV-1 are not currently available in China. Recent studies in China showed a high percentage in serological prevalence against BoHV-1 in both, cattle and yaks (Bos grunniens) (Han et al., 2016; Yan et al., 2008), which indicate a high prevalence of natural infection. Nonetheless, the virus has never been isolated from naturally infected animals or semen samples in China. 

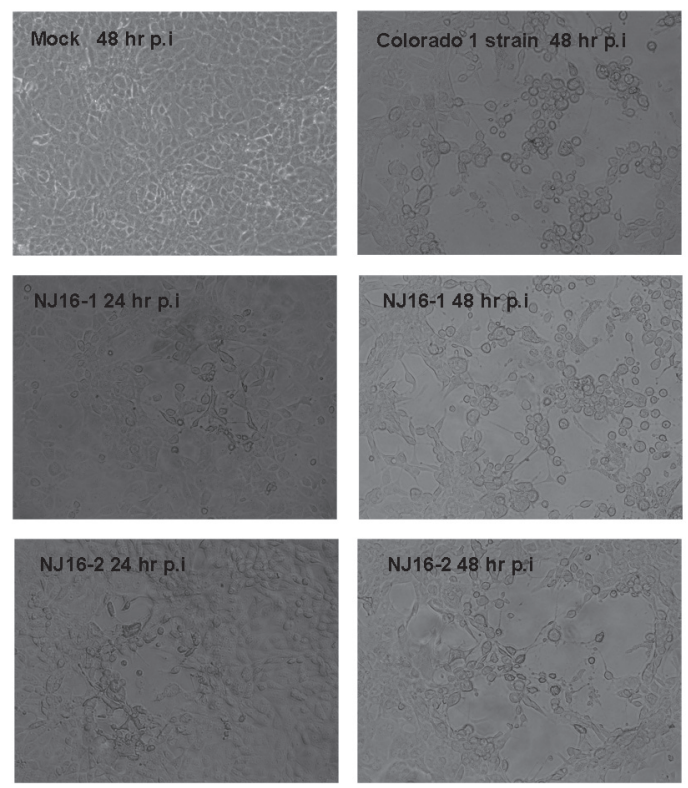

Fig. 1

The morphology changes of MDBK cells exposed to NJ16-1 and NJ16-2

Monolayer of MDBK cells was mock infected with PBS, infected with BoHV-1 Colorado 1 strain, or the second passages of NJ16-1 and NJ16-2. Images were taken 24 and $48 \mathrm{~h}$ post-infection by transmitted light microscope (Olympus BX-51), with magnification of $200 \mathrm{x}$. Shown data represent one of three independent experiments.

The aim of this study was to isolate BoHV-1 in frozen semen samples from breeding bulls in China. A total of 30 semen specimens from apparently healthy breeding

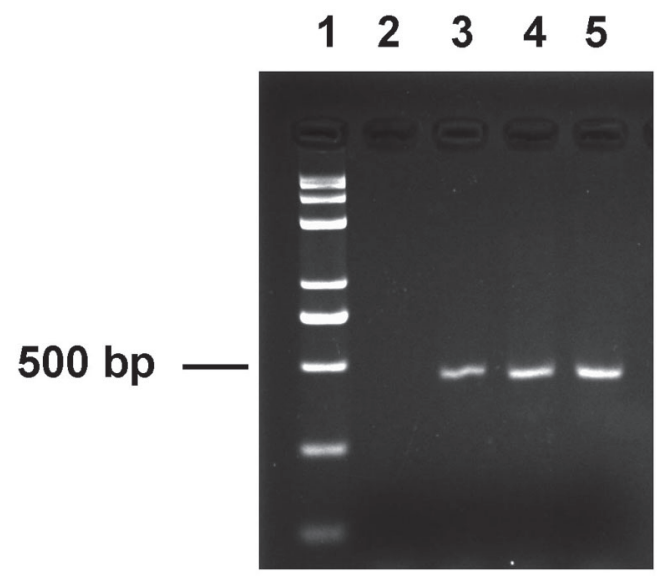

Fig. 2

The identification of NJ16-1 and NJ16-2 with PCR Lane 1, marker; lane 2, negative control; lane 3, BoHV-1 Colorado 1 strain; lane 4, NJ16-1 and lane 5, NJ16-2. The size of expected PCR product was $486 \mathrm{bp}$. Shown data represent one of three independent experiments. bulls were obtained from a frozen semen bank affiliated to Nanjing Agricultural University (China) in January 2016. No serological data regarding BoHV-1 infections were available for any of these bulls. After thawing, the samples were subjected to centrifugation at $1000 \mathrm{rpm}$ for $10 \mathrm{~min}$ at $4^{\circ} \mathrm{C}$, the supernatant was subjected to filtration with $0.2 \mu \mathrm{m}$ filter, and inoculated into monolayer of MDBK cells (kindly provided by Dr Leonard J. Bello, University of Pennsylvania) in 24-wells plates with $100 \mu \mathrm{l}$ of supernatant per each well. At $2 \mathrm{~h}$ post inoculation, $500 \mu \mathrm{l}$ per each well of fresh medium containing $2 \%$ equine serum (HyClone, USA) was replaced and further incubated for $48 \mathrm{~h}$. After freeze-thawing cycle, the cell culture was subjected to blind passages for two more times. As a result, typical cytopathic effect (CPE) of BoHV-1 infection, such as grape-like clusters of rounded cells present around a microplaque, and giant cells or syncytia (Nandi et al., 2009), were consistently observed in the cell culture with two out of the 30 samples (Fig. 1). They were assigned as NJ16-1 and NJ16-2.

The presence of BoHV-1 was detected in cell culture with PCR assay. DNA was isolated from the cell culture using a DNA extraction kit (TIANGEN, China), according to the manufacturer's instructions. PCR reaction was performed with the following primer set: forward 5'-CACGGACCTGGTGGACAAGAAG-3' and reverse 5'-CTACCGTCACGTGAGTGGTAC-3' as described previously with some modifications (Nandi et al., 2009; Vilcek, 1993). As expected, the PCR products of $\sim 468$ bp were obtained from both NJ16-1 and NJ16-2 (Fig. 2). The amplified fragments were subsequently cloned into pMD-19 simple T vector (TaKaRa, China) and sequenced by Shanghai Sangon Biological Engineering Technology \& Services. Based on BLAST search, the obtained nucleotide sequences were confirmed as $\mathrm{gB}$ of BoHV-1. The sequences from both NJ16-1 and NJ16-2 were highly homologous to gB gene of BoHV-1 reference strain Cooper (Acc. No. KU198480.1), sharing 99\% identity at the nucleotide level. Subsequently, the semen samples originating from the same breeding bulls, but from different batches were used for retrospect study for virus isolation and viral DNA detection with PCR. These results were also positive (data not shown). This confirmed that the bulls were infected by BoHV-1.

Further identification of these viruses was performed by western blot analysis by detection of BoHV-1 regulatory proteins VP16. MDBK cells in $60 \mathrm{~mm}$ dishes were infected with NJ16-1 and NJ16-2 from 3 passages with 1000x dilution. At $12 \mathrm{hr}$ post-infection, cell monolayers were washed with PBS and lysed with lysis buffer as described previously (Zhu et al., 2011). Cell lysates were separated by $10 \%$ SDS-polyacrylamide gel and transferred to a PVDF membrane. After blocking in 5\% nonfat milk, the membrane was incubated with primary antibodies against BoHV-1 VP16 (a kindly gift from Dr. Vikram Misra at the University of Saskatchewan) 


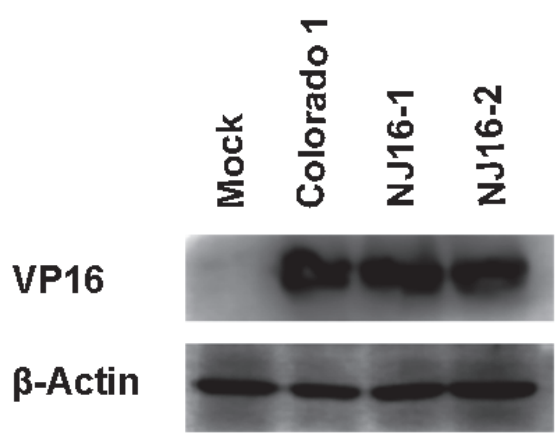

Fig. 3

The identification of NJ16-1 and NJ16-2 with western blot analysis MDBK cells were infected with BoHV-1 Colorado 1 strain, NJ16-1 and NJ16-2, respectively. At $12 \mathrm{hr}$ post-infection, the cell lysates were subjected to western blot analysis with antibody against BoHV-1 VP16. Shown data represent one of three independent experiments.

(Misra et al., 1994) and GAPDH (Cell Signaling, USA), followed by HRP-conjugated secondary antibodies in Trisbuffered saline (TBS) buffer. After being washed with TBS buffer containing $0.05 \%$ Tween 20 (TBST), the reactive bands were developed with enhanced chemiluminescence reaction (Millipore, USA) by a LI-COR Model system (Lincolin, USA). As a result, the viral protein VP16 was consistently detected in both the cells infected by both NJ16-1 and NJ16-2 at $12 \mathrm{~h}$ post-infection (Fig. 3). It corroborated the results of both PCR assay and DNA sequence analysis and confirmed that the isolated viruses were BoHV-1.

Taken together, our results suggest that samples obtained from commercially available semen samples from two breeding bulls in China contained BoHV-1. These results show that semen samples are important transmission sources of BoHV-1 virus in China bulls. To our knowledge, this is the first report of BoHV1 isolation in China. A thorough characterization of these isolates remains the subjects of further investigation. Furthermore, we suggest further nationwide studies for surveying the prevalence of this virus in the breeding bulls, as well as implementation of a mandatory eradication programs not only in the breeding bull populations but also in the commercial semen banks.

Acknowledgements. The authors would like to thank Dr. Leonard J. Bello, University of Pennsylvania, for providing the MDBK cells and the Colorado 1 strain of BHV-1, and thanks for Prof. Vikram Misra from University of Saskatchewan for providing the antibody against BoHV-1 VP16. This research was supported by Chinese National Science Foundation Grant (No. 31472172), the Priority Academic Program Development of Jiangsu Higher Education Institutions (PAPD and TAPP). Partly supported by the grant No. BE2014358 and No. 14KJA230001 from Jiangsu province, and the Agricultural Science and Technology Innovation Program (No. ASTIP-IAS-11).

\section{References}

Bielefeldt Ohmann H, Babiuk LA (1985): Viral-bacterial pneumonia in calves: effect of bovine herpesvirus-1 on immunologic functions. J. Infect. Dis. 151, 937-947. https://doi. org/10.1093/infdis/151.5.937

Darling AR, Freyschmidt EJ, Burton OT, Koleoglou KJ, Oyoshi MK, Oettgen HC (2014): IL-10 suppresses IL-17-mediated dermal inflammation and reduces the systemic burden of Vaccinia virus in a mouse model of eczema vaccinatum. Clin. Immunol. 150, 153-160. https://doi.org/10.1016/j. clim.2013.11.010

Eaglesome MD, Garcia MM (1997): Disease risks to animal health from artificial insemination with bovine semen. Rev. Sci. Tech. 16, 215-225. https://doi.org/10.20506/ rst.16.1.1017

Han Z, Gao J, Li K, Shahzad M, Nabi F, Zhan D, Li J, Liu Z (2016): Prevalence of circulating antibodies to bovine herpesvirus 1 in yaks (Bos grunniens) on the Qinghai-Tibetan Plateau, China. J. Wildl. Dis. 52, 164-167. https://doi. org/10.7589/2015-01-018

Jones C (2003): Herpes simplex virus type 1 and bovine herpesvirus 1 latency. Clin. Microbiol. Rev. 16, 79-95. https://doi. org/10.1128/CMR.16.1.79-95.2003

Jones C, Chowdhury S (2007): A review of the biology of bovine herpesvirus type 1 (BHV-1), its role as a cofactor in the bovine respiratory disease complex and development of improved vaccines. Anim. Health Res. Rev. 8, 187-205. https://doi.org/10.1017/S146625230700134X

Jones C, Chowdhury S (2010): Bovine herpesvirus type 1 (BHV-1) is an important cofactor in the bovine respiratory disease complex. Vet. Clin. North Am. Food Anim. Pract. 26, 303-321. https://doi.org/10.1016/j. cvfa.2010.04.007

Misra V, Bratanich AC, Carpenter D, O'Hare P (1994): Protein and DNA elements involved in transactivation of the promoter of the bovine herpesvirus (BHV) 1 IE-1 transcription unit by the BHV alpha gene trans-inducing factor. J. Virol. 68, 4898-909.

Muylkens B, Thiry J, Kirten P, Schynts F, Thiry E (2007): Bovine herpesvirus 1 infection and infectious bovine rhinotracheitis. Vet. Res. 38, 181-209. https://doi.org/10.1051/ vetres:2006059

Nandi S, Kumar M, Manohar M, Chauhan RS (2009): Bovine herpes virus infections in cattle. Anim. Health Res. Rev. 10, 85-98. https://doi.org/10.1017/S1466252309990028

Pawar SS, Meshram CD, Singh NK, Saini M, Mishra BP, Gupta PK (2014): Development of a SYBR Green I based duplex real-time PCR for detection of bovine herpesvirus-1 in semen. J. Virol. Methods 208, 6-10. https://doi. org/10.1016/j.jviromet.2014.07.027

Raaperi K, Orro T, Viltrop A (2014): Epidemiology and control of bovine herpesvirus 1 infection in Europe. Vet. J. 201, 249-256. https://doi.org/10.1016/j.tvjl.2014.05.040

Sharifzadeh A, Namazi MJ, Mokhtari-Farsani A, Doosti A (2015): Bovine herpesvirus type 5 in semen samples from bulls in Iran. Arch. Virol. 160, 235-239. https://doi.org/10.1007/ s00705-014-2272-3 
Tikoo SK, Campos M, Babiuk LA (1995): Bovine herpesvirus 1 (BHV-1): biology, pathogenesis, and control. Adv. Virus Res. 45, 191-223. https://doi.org/10.1016/S0065-3527(08)60061-5

Turin L, Russo S, Poli G (1999): BHV-1: new molecular approaches to control a common and widespread infection. Mol Med. $5,261-284$

van Oirschot JT, Straver PJ, van Lieshout JA, Quak J, Westenbrink F, van Exsel AC (1993): A subclinical infection of bulls with bovine herpesvirus type 1 at an artificial insemination centre. Vet. Rec. 132, 32-35. https://doi.org/10.1136/ vr.132.2.32
Vilcek S (1993): Detection of the bovine herpesvirus-1 (BHV-1) genome by PCR. J. Virol. Methods 41, 245-247. https:// doi.org/10.1016/0166-0934(93)90132-B

Yan BF, Chao YJ, Chen Z, Tian KG, Wang CB, Lin XM, Chen HC, and Guo AZ (2008): Serological survey of bovine herpesvirus type 1 infection in China. Vet. Microbiol. 127, 136-141. https://doi.org/10.1016/j.vetmic.2007.08.025

Zhu L, Ding X, Zhu X, Meng S, Wang J, Zhou H, Duan Q, Tao J, Schifferli DM, Zhu G (2011): Biphasic activation of PI3K/ Akt and MAPK/Erk1/2 signaling pathways in bovine herpesvirus type 1 infection of MDBK cells. Vet. Res. 42, 57. https://doi.org/10.1186/1297-9716-42-57 